\title{
Mick or Keith: blended identity of online rock fans
}

\author{
Andrea J. Baker
}

Received: 16 November 2008 / Accepted: 10 June 2009 / Published online: 24 June 2009

(C) Identity Journal Limited 2009

\begin{abstract}
This paper discusses the "blended identity" of online rock fans to show that the standard dichotomy between anonymous and real life personas is an inadequate description of self-presentation in online communities. Using data from an ethnographic, exploratory study of an online community and comparison groups including interviews, an online questionnaire, fan discussion boards, and participant/ observation, the research analyzes fan identity online and then offline. Rolling Stones fans often adopt names that illustrate their allegiance to the band, along with avatars. Issues of gender and the technological change of software platform also affect types of online self-presentations and their construction. Fans engage in "role embracement", merging their individual selves with the role of Stones fans, demonstrated by reactions of friends and family. Connections between offline and online settings occur, with band affiliation of fans expressed through choice of apparel offline, and usernames from online filtering into the offline interactions among fans.
\end{abstract}

Keywords Online identity · Blended identity · Online community · Username · Fans · Rock music · Online fans · Internet · Cyberspace · Role-embracement · Gender .

Goffman · Self-presentation · Construction of identity · Avatar · Virtual ethnography · Qualitative research · Web 2.0

\section{Introduction}

The Rolling Stones and fan identity

The fans of The Rolling Stones first became visible during their early television appearances and the tours in 1963, '64 and throughout the 1960's. They followed the

\footnotetext{
*Names provided in the paper are actual usernames if people gave the researcher permission to use them, or are changed or removed if the respondent preferred an anonymous form of identity. The names of the fan groups are changed.
}

\footnotetext{
A. J. Baker $(\bowtie)$

Ohio University, Lancaster, OH, USA

e-mail: bakera@ohiou.edu
} 
group known for their resistance to band uniforms and drug laws, their rebellion against the mainstream ironically in conformity with the aspects of the counterculture. They were often counter-posed to The Beatles, the nice boys, and fans frequently chose between the two super-groups, although some claimed to like both. Over 40 years later, The Stones are touring and recording and many fans are from the ranks of the old-timers who were there from the start. With the Internet available since the later months of 1994, fans found ticket buying easier, if not always fairer. They became consumers and producers of a vast amount of information on the band, and came to know each other online.

This paper is an overview of identity expression within an online fan group of The Rolling Stones. Stones fans from other groups are mentioned in comparison. The main research questions are:

- How do fans present themselves online?

- How do the online identity and the offline identity of fans inter-relate?

The purposes of the paper are two-fold, first, to delineate how fan identity may occupy a middle area between "real" and fantasy elements of self-presentation, and second, to gain insight into the mix of offline and online behaviors and attitudes among fans, or to explain how the real and virtual combine. This middle ground of fairly open self-expression colored by the group purpose may characterize a large proportion of discussion groups online that are based upon a common interest.

\section{Rolling Stones fans online and studies of fan identity}

While studies of fan behavior have become more accepted within academia in recent years in the popular culture area (see Harris in Harris and Alexander 1998, p. 4), the study of online fandom is only beginning to flourish (see, e.g., Gray et al. 2007). A notable early work about fans online is Baym's (2000) study of soap opera fans. She discusses elements of online community and tactics of communication within it. Much has been written about online identity including a large literature on the issue of deception (see e.g., Birchmeier et al. 2005; Gonzales and Hancock 2008). The normative form of identity adopted by fans submerges their individual names, without necessarily intending to deceive their online peers. Why the study of online fan identity is important to Internet researchers is two-fold: first, to learn more about the fans of celebrities, bands, and television shows who form a large subgroup of interest groups online, and second, and even more crucial for this paper, to add to knowledge on how people combine their offline presentations of self with their online interests. Because fan sites and music fan communities in particular so obviously link a group (the band or performer) to the individual (the online participant), they represent the opportunity to learn about how people relate to others with common interests online.

After the methodology section detailing how the research was conducted, the major topics include descriptions of fan usernames and avatars, the effect of technological change in the fan sites, and a discussion of the concepts of "blended identity" and role embracement. A summary of findings and future directions for research concludes the paper. 


\section{Methodology}

This research is part of a larger project on identities, relationships and norms of an online fan community. It follows the methodological tradition of qualitative research in sociology (Denzin and Lincoln 2007) that draws upon the ethnographic method employed by cultural anthropologists (see Geertz 1973). Also called "field work" or "participant observation", ethnography traditionally aims at describing and analyzing the behaviors and attitudes of the participants in the collectivity, their customs and perceptions. Often the researcher becomes a member of the group, or is already a member at the time of initiating the research, as in this project. Online researchers have transposed this methodology to online settings, engaging in "virtual ethnography" (Hine 2000). Studies of online communities using the ethnographic, participant observer method include Nancy Baym's (2000) depiction of Internet soap opera devotees, fans of these daily television shows, as indicated above, and Rheingold's (1993) classic book on THE WELL, The Virtual Community, which included reference to both online and offline events and relationships. Baym and Rheingold were both participants in these communities before they began to write about them, as was this author.

The qualitative methodology here is a combination of a two-year ethnography or participant observation in a discussion board and in offline events, an online questionnaire posted for members of the targeted online group, and interviews with online fans, including members of the targeted online community and also interviews of people from three other groups. Some of the respondents belonged to more than one group. The targeted group "Shattered" has several thousand people who have registered, with a few dozen or so who do most of the daily posting. The other groups are mainly smaller than Shattered, with one that has a larger number of registered members, "You Got Me Rocking" (YGMR). The primary source of data for this paper is from 89 interviews with online fans, three-quarters of whom are on the Shattered discussion board, and one-quarter from the other groups, predominantly YGMR.

After a period of a year or so, the researcher decided to study the online community Shattered, with the permission of the head of the group. He announced a separate forum for those interested in answering open-ended questions about their experience with The Rolling Stones and their online community. The researcher posted questions in the forum that some members read and chose to answer. The other three group leaders gave permission to contact members for interviews, and in two cases, offered to help further with the project. The data from the interviews, conducted mainly by phone, is added to that from the forum answers. Interviews lasted approximately an hour and 15 minutes apiece, with some taking two, three or more hours, when fans had longer histories with the Stones, or remembered many details they wanted to include. The public threads about concert events and facets of the Stones' lives and performances were also read for the larger research project, and for clues to identity discussed in this paper.

As part of this qualitative project, the set of interviewees was not selected randomly from the population of online fans. Drawing from the total number of people who have ever signed up for the online community in its ten-year existence $(n=5,706$ on May 3,2009$)$ would miss the fact that only a relatively small group of 
members actively engages regularly. For example, the average number of messages per day is 128 , with a small group writing multiple daily posts. Guests can read without creating an account with a username, and guests along with registered members often lurk instead of joining the discussions by posting. Rather than numerical quotas, the method here follows "theoretical sampling" (see Glaser and Strauss 1967) whereby categories of people including the more active members to less active online are noted. About two-thirds of those asked for interviews agreed to them, although some of those who declined the interview did answer the questionnaire. Those from a range of fan communities and across ages and geographical territories were queried, either by interview or a questionnaire online. The fans range from ages 18 to 63 and come from countries all over the world, though mainly located in North America, and secondarily, Europe.

For the sample in this article, the 89 interviews occurred primarily by telephone, although a few took place in person or through chat. They came from four different online fan groups, some with overlapping membership. Different numbers of people from one group Shattered, answered all or some of the questions posted online. The mean number of postings for the forty questions was thirty-five, with a median of thirty-two answers per question. One or two questions were put up at a time, with some drawing more written response than others, depending upon interest in the question and when it was posted. The questionnaire served to explore types of responses to basic inquiries and formed the basis of the more developed set of interview questions.

Questions specifically related to identity in the questionnaire and interview guide include, "How did you select your username?" and "How did you select your avatar?" Related questions asked about members' favorite Rolling Stone, why they liked the band's music, and how friends and family reacted to their fan behavior. The data presented here on usernames, avatars and responses of others is drawn from the questionnaire, while the information about offline behavior comes from the interviews, unless otherwise noted. In qualitative methodology, the data analysis often happens concurrently with the data collection, with the findings emerging directly from that process (see Becker 2004).

\section{Rock fan identity online: username, avatar, and favorite band member}

Fan identity online: the username

The typical identity presented through the username on the board Shattered is of a fan of The Rolling Stones, since that is the purpose of the online place. Shattered is a gathering spot for people who like the band's music and often, who also care about the performers themselves. By taking a phrase from a song lyric or an album title, using all or part of a band member's name, or by referring to a place or person associated with the band, the members want to demonstrate a liking for the Stones through their selected names. The user's name or ID often depicts the merging of the individual and the band.

A high degree of admiration of the band causes someone to identify with the band through self-naming. Whether it is the music itself, the onstage and recorded 
musicianship and performances, or the perceived personas of band members that so excites the fans is an empirical question. The interview data indicates all three elements are parts of the attraction to the band. The username suggests close familiarity with the music and also a liking of the band members themselves. To name oneself tells others something about where the liking is most focused, whether in a favorite song, or a favorite band member.

One issue that arises online is when two people choose similar user IDs. They cannot be exactly the same because the technology prevents two people from having identical names. As on many discussion boards online, if a person leaves or is taken off because of inactivity or disruption, the name can become available again. When the original user reappears and wants the name back, conflict can occur. Users watch out for each other by telling people online and offline when a particular name "belongs" to someone else, by right of seniority. Numbers are used, as elsewhere online when a name is very popular such as "angie75", a user id drawn from the well-known Stones song with the same female name in the title.

The amount of creativity in name-selection is admired, along with the longevity that having a popular name implies. The popular names include band members' names or variations of them. One Dutch fellow, Mickijaggeroo, took his moniker from a video in which the Latino shopkeepers have trouble recognizing the lead singer until he plays a Stones album and dances to his own music. They chant, "Ah, Mickijaggeroo, Mickijaggeroo!" upon realizing who is in their store. Sometimes abbreviations are considered almost too innovative, until people come to know a person online and off, as was the case with IRLTS, an abbreviation for "I really love the Stones." Remembering the acronym proved difficult, at first, for online fans, and pronouncing it offline, even more so. The user's first name, a one-syllable, fairly common man's name is often used to address him offline.

More typically, a song title becomes the name, such as the song "Under Assistant West Coast Promotion Man" shortened to "Promo". Album titles, ("Exiled", short for "Exiled on Main Street", for example), along with various names and numbers attached) or song lyrics can become names, although the lyrics more commonly appear in signature lines, words appended to members' posts. Examples of other song titles as usernames are "As Tears Go By", "Sweet Virginia" and "Saint of Me", whereas lyrics include "a kiss away", and "man of wealth and taste" (both from the song "Sympathy for the Devil") usually written in the one word form for the nickname, without spaces.

A contrast between the main group under study and the others is how often a person's real name is placed between the band and the individual. In groups outside of Shattered including the European-based You Got Me Rocking (YGMR), the private email list Under My Thumb (UMT), the small, informal group, Monkey Man (MM), and to a much lesser extent on Shattered, either a general name is used that promotes music or another name defining a personal characteristic or interest, or a part of the person's real name, such as a first name or a nickname is commonly employed as the user ID. The more a person emphasizes themselves as opposed to the band, the more generalized the identity is to the person and other facets of his or her identity rather than representing an allegiance to the band.

The head of the online community Shattered uses an amalgam of his own name and the band, "Stonesdoug"*. There is no doubt about his commitment with this 
name, chosen when he went online at AOL before forming the starter group there. He describes his online choice this way:

I was going to use a Stone's song as my moniker, but then remembered a girl I used to hang with in college named Julie. Whenever we were at a party, she would say "Stones, Doug, let's boogie" and we would get up and dance. So it seemed to fit and Stonesdoug was the first name I ever had on the internet.

The name fit perfectly when he decided to split off from an AOL group devoted to Stones discussion to form his own fan board with a separate server, and his name became one model for others joining later.

The avatar: pictorial counterpoint to the username

Because the new site on Yuku.com makes it easier to have an avatar, and since the default is a generic person in silhouette, most people who post frequently will identify themselves with a photo, cartoon, artwork or graphic symbol. Sometimes the avatar will echo the username, if the username repeats the name of one of the band members or has the band name in it. One person said that since people become known more by the picture than the name, the identifier on first glance, changing the avatar is probably not wise. The avatar, perhaps more than the username, actually shows the personality of the individual and the nature of the identification with the band.

A few people post actual photos of themselves, most often with band members, if they have met them and had their pictures taken with them. These photos serve two purposes, (1) to show they've literally come close to the subjects of the board, and (2) to allow others to recognize them offline. Others employ one from the large array of tongues symbolizing the band, either in the traditional red color or in other colors or permutations such as the spiky tongue, the Babylonian tongue or the multi-hued "Licks" tongue. Every tour generates more designs of the tongue, so the type of tongue shown is associated with a particular date of origin, known from when that Stones tour began or progressed.

Pictures of band members are most often photos taken either by the fan or by photographers throughout the band's history. Fans also use cartoons, drawings or paintings of individual musicians or combinations of them. Women more often choose photos of Mick while many men pick photos or drawings of Keith. Cases occur where the gender of an online fan is unclear, unrevealed by seeing the username and avatar, since both men and women draw mainly upon male symbols in text and graphics.

One form of identity: Who is your favorite Stone, Mick or Keith?

Of the four major Rolling Stones, the two most well known are Mick (Jagger) and Keith (Richards), meeting as schoolboys to join Bryan Jones and a few others to form the band in the early 1960's. They are the composers and lyricists of almost the entire Stones catalogue. Along with them is the drummer, there since the beginning, Charlie (Watts) and the second guitarist after Keith, Ronnie (Wood), called "the new guy" or "the new boy" in the UK with his 32 years of service of the 47 years of the band's existence. 
Fans line up in their loyalty behind Mick or Keith, in most cases. Keith fans try to get seats on "Keith's side" of the stage as opposed to "Ronnie's side". They treasure owning one of his guitar picks, thrown out by Keith at intervals during a show. Ronnie's side is seen as second-rate for Keith fans. Mick tries to cover all sides of the stage, and sings at least the beginnings of songs in the center area, so Mick fans will sit anywhere. Most fans prefer to sit as close as possible, given high ticket prices and the frequent scarcity of good seats.

Each of the two men represents different parts of a spectrum of characteristics or personal qualities, most often dichotomized. Depending on the allegiance of the fan or writer, the words contain positive or negative slants toward one of the two. With Mick first in the pair, and Keith second, we see from the Keith fans point of view: cold vs. warm, controlling vs. easy-going, planned vs. spontaneous, and, with a more favoring eye toward Mick: responsible vs. irresponsible, concerned vs. uninvolved, front man vs. guitarist. Keith is viewed as the more emotional guy, the "heart" of the group, and from the Keith fans' perspective, Mick is a good performer but not someone they relate to as a person. From the extremely devoted Mick fan's standpoint, there is no one else except Mick to consider when looking at the band. In the words of one fan, only half joking, "All I see is Mick".

The genders split somewhat with many men preferring Keith and more of the women siding with Mick. There are many exceptions, however, and among the females the Mick admirers call themselves "Mick chicks" and the Keith adorers are known as "Keith babes". More of the men are amateur musicians, and occasionally, even professional band members. They have analyzed Keith's skill on his instrument, his technique earning him the name "the riff-master". The overall gender distinction is that, as the fan saying goes, men want to "be" the Stones, whereas women want to "know" them or "f_ck" them. One respondent said that men like Keith and women like Mick. In the researcher's online questionnaire with a self-selected sample, Keith was the favorite of about half the respondents, Mick one quarter, and the others or combinations of members another quarter. Slightly more men than women chose Keith, with the reverse for Mick.

The co-leader of the board is a self-identified Keith fan, "oldkr" who has run his own board dedicated to the guitarist. A long-time member theorized that the online community Shattered had become more oriented to Keith since oldkr took over coleadership a few years after the board started. Reflecting the questionnaire results, a much larger poll on another site YGMR taken by the group leader showed Keith garnering half the votes for favorite, Mick with 28 per cent, with others getting smaller shares of the overall vote. No gender breakdown is available for that poll.

Usernames can announce to the other fans which of the Stone is favored. Are you a Jaggrsfan, or a keefriffhard? People have chosen nicknames that use their own first names such as VirginiaJagger or KurtRichards. Sometimes the names are genderneutral, placing the individual's band member affiliation above any revelation of a person's gender in the public identity. Usually men rather than women take on the first name or whole name without other adjectives, so that onlookers can be fairly certain that CharlieBWatts is male. Jaggrsfan is in fact a female, but aside from a perceived tendency of females to lean toward Mick, the gender is left ambiguous. Someone who likes the whole band such as Stones75, referring to the year of his first Stones concert can be of either gender, or for example Stones100LightYears, 
named for a song. Jaggedm is named for Mick's production company "Jagged Films", with the first initial appended for clarity.

\section{Technological change and online identity: moving into Web 2.0}

Technology has definite effects on online interaction, including the provision of the basic modes of relating (see, e.g., Blanchard and Markus 2007). The format of the profile changed between two software platforms. The ezboard platform had housed a "variety" of discussion boards for a number of years until Yuku purchased it. After the beta version was tested in 2006, site administrators and users had no alternative except to switch from ezboard.com to Yuku.com. Yuku took ezboard's place to house the Shattered discussion board, and, with its added features for fans on Shattered is more friendly to Web. 2.0, The new platform made posting an avatar much easier, leaving out the steps of going to Photobucket.com to retrieve a photo or picture posted there to allow posting directly from the member's desktop. This change led to more sophisticated avatars than on the old board, to more varied photos and artworks, rather than so many tongue symbols. The new profile encouraged members to "friend" someone, as well as message each other. Once someone accepted the friendship, that person's picture would appear under "friends", if the person chose to reveal their friends. In this way, Shattered became much more like the social networking places MySpace or Facebook, with the friendship option.

There is also a new feature, a system of "kudos" both for profiles and threads for people to show their respect for a member. However, how people achieve the different types of kudos listed by the system is not clearly understood by many of Shattered's readers. A member since the start of Shattered said:

I'm not really sure how the whole thing works... You can give kudos by clicking on their profile \& giving kudos that way. You can also kudo a thread, but I'm not sure how that affects your personal kudo total... I still have no idea how you increase the charisma kudos either...

From time to time, the fans mention how people seem to receive kudos just for joining, rather than through individual members deciding they deserve them. The kudos feature may work as an adjunct to number of friends a person has too, since the more people checking a profile, often triggered by "friending" them, the more kudos potentially received.

In the early months of Yuku implementation, if a person started a topic or thread, the topic itself could receive kudos, as mentioned above. Whether or not those were added to individual profile kudos is unknown, as noted above by the fan. The site leaders disabled this feature about a year after trying it.

Old-timers started topics to help each other become accustomed to the new ways of doing things, such as the thread called "Yuku or whatever", which ran for 9 days, housing many complaints, as users adapted. Within weeks, the change seemed almost forgotten, except for the username and cartoon avatar of "Yukuman" put up by one fan. The majority of people seem to prefer the new system, after some initial problems with the chat feature. 
A change in technology can affect how members present identity online, (see Blanchard and Markus 2007) epitomized in their online profiles. These personal profile pages are accessed by a link under each member's name at Shattered. The background of the profile in the new system is fairly easily replaced, not just with a few set themes provided with the platform, but also with customizable wallpapers, leading to a greater individuality of profiles. People can change these elements quite quickly too, as often as they like. Another feature is that people can post a photo album and also videos, an option not included in the old profiles. The new profile allows people to show their friends, and their recent posts and comments from others, unlike the old profile.

The look of the board remains the same, with the same general forums or general topics appearing for people's posts. The board administrator has occasionally tried to clean out a few threads or forums to more or less agreement or objection. When he took away a regional forum for lack of posts, denizens of those topics protested so he put it back. It happened that a person who was sick had posted updates there, and he was moved to more currently and consistently read forums.

Along with the ability to add friends, photos and videos and make them visible in the profile, another change toward Web 2.0 is how some leaders have started their own pages at MySpace or Facebook. Both Blue Lena, a co-editor of an international fan club magazine and Stonesdoug have established the presence of their groups outside of their original websites. People visiting those social networking sites (SNSs) often have overlapping memberships with the fan clubs, but sometimes they are solely or mainly active on the SNSs. Also, members of YGMR have recently started topics inviting fans to join them at their pages on MySpace, Facebook, and Twitter.

\section{Discussion: blended identity and role embracement}

Blended identity I: presentation of self in cyberspace, between real and virtual

\section{Blended social identity online}

The concept of "blended learning" has appeared in the literature on online education for years (see e.g., Kirschner et al. 2006). It means that a combined form of instruction takes place in both the virtual world, online, as well as in the physical classroom. Following Walther and Park's (2002) notion of "mixed mode relationships" to denote connections that span the online and offline worlds, here the concept of "blended identity" refers to online self-presentations that include both online and offline aspects of individuals. To understand the process of the creation of blended identity is to know how people (a) derive identities online related to their offline experiences and the online community they have joined, and then (b) migrate from online to offline bringing with them the online identities that they then introduce to others whom they have met first online.

This paper stands within the sociological traditions of defining "social identity" in relation to social roles and group memberships in contrast to "person identity" (see Brekhus 2008), based upon personality characteristics, and more within the purview of psychology. There is some overlap between person(al) and social identity in the 
area of self-expression of the individual both within and outside of actual groups or communities. The "interactionist" brand of social psychology in sociology (see Blumer 1969; Goffman 1959, 1963) "situates" identity within an actual, everyday situation in present time to look at how the person adapts to the environment. This perspective applies to analysis of individuals within online settings along with faceto-face (f2f) situations, as researchers have discovered (see Miller 1995).

The importance of "place" or location online is similar to an offline setting, in that the goals of people drawn to a particular space, and the modes and styles of interaction are greatly affected by the conventions of the particular online space (Baker 2008). For example, people meeting online either in a dating site or in a more naturalistic (McKenna 2007) manner in a game, chat room or discussion board engage in very different processes to become acquainted and to set up offline meetings (Baker 2005, 2008). If a relationship begins, for example, on an Internet dating site, the pair will meet relatively anonymously, limited to what each puts down in their profile. However, if the two become attracted while participating in a virtual world, a game, or in an online community, they may well already know quite a lot about each other's style of communication and depth and breadth of interests. In relation to anonymity, some places, usually private communities, require completely transparent identities, whereas others assume differing degrees of anonymity.

\section{Authenticity of the blended identity online}

People on Shattered engage in various forms of self-presentation through choice of name and avatar. Much of it shows off the commitment to the band, while some of it exhibits individual qualities of play or humor. Self-named for the song, "West Coast Promo Man" one fan, mentioned above, changed his name to the much briefer "Promo" after encouragement from others who preferred the shorter nickname. The somewhat obscure user ID "Arthur" came from a break in a recording session when Mick used that name for Keith, when he was slow coming in, possibly due to Keith's real or imagined "arthur-itis" at the time. Some usernames and avatars directly portray the actual individual through use of first names (more rarely last), and photographic portraits of themselves. How much people intend to purposely hide their true identity is unknown, since the choices may reflect allegiance to the band and follow the lead of the founder, who combines his first name with the band: Stonesdoug, as noted above. The comparison sites contain members with varying degrees of blended identity, with some also following the leader's cue. At YGMR, the leader's username is his first and last initials. Some members of this group use a form of their real names, and some have nicknames, often related to music, such as "Rockman". Still others resemble Shattered in employing a mix of Stones-related names such as "angee" for the song "Angie", "mickxgrrl", about the favored band member, and "Edith Grove", a place of residence for the early Stones, a name well known to Stones buffs.

A point here is that conceiving identity solely in terms of honesty or deception is misplaced where people can choose a variety of names in an online community, especially when the group's goal is to explore the particular interests of the members. Community norms may work against total transparency or revelation of RL (real life) names in favor of more colorful handles. Several people mentioned 
how they were told by other members to find a Stones-related name. The process of choosing a username then, can operate independently of conscious deception.

Researchers of identity issues in online relationships, communities, and social networks have often concerned themselves with the degree of deception or honesty of self-presentation (see, for example, Donath 1999). When people intend to meet offline, a degree of openness or honesty is much more common than when they do not (Walther 1994). Here many respondents speak of wanting to meet people face-toface they have seen on the discussion boards, and of forming friendships with those they have encountered at shows or "pre-parties" before concerts. Data from this project indicate a middle ground of openness, with a desire to show a bond with the particular musician or to the music itself among the most common reasons for choosing a board name and avatar. This preference situates the fan among other fans, both similar and different. Tailoring the avatar and user id to characteristics of the particular individual is another goal of members. Usernames are sometimes used offline in preference to real names and sometimes not. When asked, do people call you "JJ" or "Stu" offline, one Shattered member answered, "They call me JJ", for Jumping Jack (Flash), the wellknown song title. The interplay of "real" or offline identity with online identity becomes a subject of interest to fans, since most will want to meet with others offline.

Blended identity II: presentation of self offline, "I'm with the band"...

\section{Fantasy offline: part of the band?}

For many fans there is a fantasy element of hanging out with the band, or sometimes even being a band member or a wife or lover of one of the members. At one concert in Las Vegas, a woman who appeared around 50 years old professed to me that she was the wife of one of the band members. I knew she wasn't, from photos I had seen, but for one second I believed her. She did look a little like Ronnie's spouse.

People IRL (in real life) often present themselves to others with a style meant to appeal to the band or to other audience members, especially when attending concerts. The general style is of a rock fan, not too formal or preppy. Those from each fan group tend to have a look, with members of Shattered wearing more Stones-related apparel. One female from that group was even cut from the extras for the Stones concert film directed by Martin Scorsese when she wore garments with too many Stones logos or tongues. The casting director said she was covered with them, not the look wanted for the film. The group Shattered has a series of its own t-shirts, the most visible and perhaps the most recognizable of all t-shirts worn by fans, because of their neon lime green color. A fan named CindyC described a preconcert gathering set up by the YGMR group and said finding people in the bar was difficult because it's "not like a Shattered crowd where you can see them wearing the shirts". In contrast, a woman from YGMR board said that she only wears subtle forms of identification when she knows she is going backstage or to a gathering where members of the band may appear. She wears a silver handcuff bracelet with large links resembling Keith's own wrist-wear. Those who have met any or all of the band members more than once seem to agree on a subdued style of apparel that suggests that regalia with obvious Stones tongues or logos is unnecessary at best or considered tacky at worst, at least when invited into more private spaces. 
One person wore a shirt to a concert that was exactly like Mick's black "Omega" top paired with his Uncle Sam hat when performing in 1969, immortalized in many photos. Less than a year later, the same fan was performing in a cover band, playing Mick. In their opening show at Fenway Park in Boston (2005), the Stones actually invited a cover band, The Rolling Stone to play with them onstage. Members of cover bands represent the closest approximation to Stones band members, although there are two types of cover bands, those that just play the music and those that imitate the looks and sounds of all or some of the band members (Kurutz 2008).

Role embracement of the fans

\section{Commitment to fan role}

"Role distance" and "role embracement" are concepts Erving Goffman applied to how committed or detached a person is from a role (Goffman 1961). With the Stones fans, the comfort with the role appears great when the person is among other fans. Like a good theater actor, the individual person disappears into the fan role, still retaining some individuality, identifying the self with the role. According to Goffman (1961), the person embracing the role "disappears completely into the virtual self available in the situation" (p. 36). Certain occupations such as the traffic officer at a crossroad during rush hour or the baseball team manager during a game illustrate full role embracement. Here, with the Rolling Stones fans, the attitudes, the music, and the apparel telegraph the fan's alliance with the band and with other fans during concerts or other events planned by and for the fans. The behavior is active and spontaneous, typical when the role "matches" the person. Apart from those occasions, he or she has a varying degree of comfort with the role, in identifying with the role, and then may move toward various degrees of "role distance" or disassociation with the role of fan.

\section{Presentation of fan identity to friends and family}

The fans answering the questionnaire online have a variety of responses to questions about reactions of friends and family. Fans who are involved enough to go online and post in a fan group are typically more committed than others, going to more shows, and reading more material about the band, for example. Also, participation in board discussion added to their fan interest in the Stones. Almost everyone answered "yes" to a question on whether or not that their membership in Shattered had increased their attendance at concerts. They commonly reveal their interest to people they know and have learned how to handle it.

Reactions range from complete support from people who share the devotion to understanding (positive reactions) to grudging toleration for the fan's preference, to a lack of comprehension of the fan's motives (negative reactions). Examples of contrasting types of reactions follow here, from the online questionnaire:

(Positive):

My parents were always fans...but never attended a show until I took them... There is absolutely no one I would NOT tell. All my friends, family, and co-workers know. 
I tell pretty much anyone who I think might be interested in my love for the Stones. My close friends know and they think it's great and are even surprised to think I'm such a fanatic. My family knows and my younger sister has even attended a show with me in ' $78 \ldots$

hell, even the corner vegetable-stand lady knows i love the Stones! and i get a lot of the same reaction as Jaggrfn mentions: people saying they wish they had something in their lives that gives them this much joy and energy. i keep telling 'em to go right ahead and love the Stones too-that's what they're for!

(Negative):

my wife wonders what the hell $\mathrm{i}$ am doin on the computer. she likes the stones but they don't move her, she never really got into them which is amazing cuz she's from the philly area and passed on so many great shows... my brother is a fan and will go anytime i buy him a ticket...some of them who have seen the band play back in the seventies can't understand (why) i'm still goin, the others look at me with bewilderment: lol

Shattered probably comes up in my conversation more [with non-fans.] Sometimes I may convey something I have read or learned on the site. I have to go into a little explanation of what Shattered is. Some people have seemed like they thought it was a little odd when I talk about people that I "don't really know”.

The fan persists despite occasional ridicule. The interest is eventually seen by most family members and close friends as something that is an integral part of the person and so not amenable to change. In the words of one fan in answer to whether anyone ever gave her a hard time about her passion: "Of course....people love to criticize the Stones. I don't listen to them." Another agrees, "You betcha-mostly co-workers-I just laugh it off! :rolleyes". The close associates recognize the extent of the fan's role embracement.

A note on gender, identity and behavior of fans: beyond Mick and Keith

For women, there is usually a different kind of identity or behavior, anyway, toward the band. Women wish to bond with the band members and men wish to identify closely with them. Women critique the appearance and behavior of the wives and girlfriends of band members, as do the men, but women overtly or covertly compare themselves with the intimate partners of the band.

While some fans say there are few if any gender differences, many point out how females concentrate on the band members rather than the technical aspects of the music. Many agree that men collect recordings, especially imports of live shows, more compulsively, or exhaustively than women. With the rare exception, men more than women analyze the actual guitar playing, the instrumental work of Keith and Ronnie.

The gender-neutrality of some names, such as song titles, can disappear when checking someone's profile if a "real name" is listed or if gender is identified. The other fan boards don't have the capability of revealing as much information as Shattered provides. This site has optional categories for name, location, gender and age in its profiles. Most people choose not to tell their real names, remaining 
anonymous unless they meet others offline. In those cases, some refer to each other online by their real first names. The private email list assumes everyone is open to sharing their real names, either in the email address or when signing their posts on the lists.

\section{Conclusions: the internet, fans and directions for future research on identity}

Findings here shed light on how attention to a band gives rise to a self-presentation that brings together individual preferences in music and performers as they exist in RL to bond in a group online. These online fan groups represent the Internet counterpart to offline audiences, and are drawn from the core fan base around the world. Researchers can benefit from analyzing how people's online activities affect the offline and vice versa. More concretely, gathering personal accounts enhances understandings of websites, while observing the content and flow of online discussions promotes more meaningful construction and analysis of individual interviews (see Orgad 2008). The concept of the "blended identity" of fans emerged directly from observing the online interactions, both during a tour and in between tours. Interviews and the questionnaire helped connect the online identities to the offline behaviors of concert going and the collecting of Stones music and paraphernalia by relating the online identity choices of participants to their offline experiences.

Blended identity and role embracement can reinforce each other. People who choose usernames containing Stones lyrics or names of band members may signal both their love of the band over their other interests or individual characteristics, and also their commitment to living out their fandom through various avenues. More study can perhaps see in detail how much their "embracement" of the Stones fan role affects other aspects of their online and offline lives, such as friendship choices, and patterns in music listening, and how other fans influence the type of username and avatar of online fans. Home décor and apparel reflect attachment to the role of fans in the form of wall art and other artifacts with photos, paintings, or graphic symbols of the band.

The effects of the Internet on fans are felt on two fronts: connecting them more easily with the objects of their fandom through websites created to fulfill commercial, informational, and social goals, and allowing them to communicate with each other individually across time and space through online tools. From email and private messaging, and from their usernames, avatars, profiles and postings in the discussion boards of the fan websites, fans can learn about each other, as well as the band. Participation in Web 2.0 also allows for relationships between and among fans and band members to spread into through social networking on sites such as Facebook and MySpace. The main site researched here, Shattered, also has mechanisms to "friend" others from the site. An area for future exploration is when and how the social networking systems interact with more traditional online spaces such as discussion boards and listservs to enhance the fan experience.

Future research on online identity can benefit from moving beyond the bifurcated typology of honesty vs. deception in self-presentation. Perhaps the default today, at least for groups with common interests, is the blended identity type, where elements of online and offline selves combine to reflect the role of the online community member. Scholars may want to look more into the degree of commitment of the 
online community member, the connections both to the online groups and to the offline counterparts of them. Continued study of identity as it is demonstrated in the blurring worlds of online and offline interaction can show us how the Internet affects people's interactions, habits, and interests they move further into the 21 st century.

\section{References}

Baker AJ. Double click: Romance and commitment among online couples. Cresskill: Hampton; 2005.

Baker AJ. Down the rabbit hole: The role of place in the initiation and development of online relationships. In: Barak A, editor. Psychological aspects of cyberspace: Theory, research, applications. Cambridge: Cambridge University Press; 2008. p. 163-84.

Baym N. Tune in, log on: Soaps, fandom, and online community. Newbury Park: Sage; 2000.

Becker H. The problems of analysis. In National Science Foundation. Workshop on scientific foundations of qualitative research. Report prepared by: Charles C. Ragin, Joane Nage, Patricia White for the National Science Foundation: Sociology Program; Methodology, Measurement \& Statistics. 2004. p. 45-47.

Birchmeier Z, Joinson AN, Dietz-Uhler B. Storming and forming a normative response to a deception revealed online. Comput Hum Behav. 2005;23(1):108-21.

Blanchard A, Markus L. Technology and community behavior in online environments, presented at the 3rd International Conference on Communities and Technologies, Michigan State University, Lansing, MI, June 28-30, 2007.

Blumer H. Symbolic interactionism: Perspective and method. Berkeley: University of California Press; 1969.

Brekhus WH. Trends in the qualitative study of social identities. Sociology Compass. 2008;2(3):1059-78.

Denzin NK, Lincoln YS. Strategies of qualitative inquiry. Thousand Oaks: Sage; 2007.

Donath JS. Identity and deception in the virtual community. In: Smith MA, Kollock P, editors. Communities in cyberspace. London: Routledge; 1999. p. 29-59.

Geertz CC. The Interpretation of culture. NY: Basic Books; 1973.

Glaser B, Strauss A. The discovery of grounded theory: Strategies for qualitative research. New York: Aldine De Gruyter; 1967.

Goffman E. Presentation of self in everyday life. New York: Doubleday; 1959.

Goffman E. Encounters: Two studies in the sociology of interaction. New York: Allyn and Bacon; 1961.

Goffman E. Stigma: Notes on the management of spoiled identity. Englewood Cliffs: Prentice-Hall; 1963.

Gonzales A, Hancock JT. Identity shift in computer-mediated environments. Media Psychol. 2008;11 (2):167-85.

Gray J, Sandvoss C, Harrington CL, editors. Fandom: Identities and communities in a mediated world. New York: New York University Press; 2007.

Harris C, Alexander A. Theorizing fandom: Fans, subculture and identity. Cresskill: Hampton; 1998.

Hine C. Virtual ethnography. Thousand Oaks: Sage; 2000.

Kirschner PA, Sweller J, Clark RE. Why minimal guidance during instruction does not work: An analysis of the failure of constructivist discovery, problem-based, experiential, and inquiry based teaching. Educ Psychol. 2006;41:75-86.

Kurutz S. Like a Rolling Stone: The strange life of a tribute band. New York: Broadway Books; 2008.

McKenna KY. A progressive affair: Online dating to real world mating. In: Whitty M, Baker A, Inman J, editors. Online Matchmaking. Basingstoke: Palgrave MacMillan; 2007. p. 112-124.

Miller H. The presentation of self in electronic life: Goffman on the internet. 1995. (available online): http://74.125.95.104/search?q=cache:kyJvQYQqrbYJ:psicopolis.com/psicopedia/selfweb.htm+the + presentation + of + self + in + electronic + life + goffman\&hl=en\&ct=clnk\&cd=3\&gl=us\&client=safari.

Orgad S. How can researchers make sense of the issues involved in collecting and interpreting online and offline Data? In: Markham AN, Baym NK, editors. Internet inquiry: Conversations about method. Thousand Oaks: Sage; 2008. p. 33-53.

Rheingold H. The virtual community: Homesteading on the electronic frontier. NY: Basic Books; 1993.

Walther JB. Anticipated ongoing interaction versus channel effects on relational communication in computer-mediated interaction. Human Commun Res. 1994;20(4):473-501.

Walther JB, Parks MR. Cues filtered out, cues filtered in: Computer-mediated communication and relationships. In: Knapp L, Daly JA, editors. Handbook of Interpersonal Communication. 3rd ed. Thousand Oaks: Sage; 2002. p. 529-63. 